\title{
Balloon and Lear Jet Testing of SCARLET Modules and Cells
}

\author{
Michael I. Eskenazi \& David M. Murphy \\ AEC-ABLE Engineering Co., Inc. \\ Goleta, California 93117 \\ Bruce E. Anspaugh \& Robert L. Mueller \\ Jet Propulsion Laboratory \\ Pasadena, California 91109
Dave Brinker
NASA Lewis Research Center
Cleveland, Ohio 44135 \\ Mark J. O'Neill \\ ENTECH, Inc. \\ Keller, Texas 76248
}

\begin{abstract}
This paper presents test results from SCARLET (Solar Concentrator Array with Refractive Linear Element Technology) experiments performed on several Lewis Research Center Lear jet flights and two JPL balloon flights. The tests were performed in support of the BMDO sponsored SCARLET II program, which is building a $2.6 \mathrm{~kW}$ SCARLET solar array to supply the primary power for the JPL New Millennium Deep Space 1 Mission. The experiments involve TECSTAR dual junction $\mathrm{GalnP}_{2} / \mathrm{GaAs} / \mathrm{Ge}$ cells flown bare and under two different types of SCARLET lenses. The two types of lenses tested were a developmental design consisting of monolithic THV fluoroplastic and the current baseline flight design consisting of ceria-doped microsheet and silicone. Measured lens and total module efficiencies are presented and the flight data is compared to various solar simulator test results.
\end{abstract}

\section{Introduction and Background}

SCARLET, as shown in Figure 1, is a concentrator solar array for space applications which uses linear refractive concentrator lenses to focus sunlight onto spaced rows of solar cells. For a given power level, the SCARLET optical system reduces the required solar cell area by approximately a factor of seven. The decreased cell area significantly reduces solar array cost and weight especially in high radiation environments where thick cell coverglass is required.

The BMDO Innovative Science and Technology Program is funding AEC-ABLE Engineering Co., Inc. (ABLE) to design and manufacture a $2.6 \mathrm{~kW}$ SCARLET solar array for NASA's first New Millennium Deep Space flight, called "DS1," which will be launched in July, 1998. The DS1 SCARLET solar array is shown in Figures 2 and 3. ABLE's 
primary subcontractors on the DS1 SCARLET program are TECSTAR, who is supplying dual junction Galn $\mathrm{P}_{2} / \mathrm{GaAs} / \mathrm{Ge}$ cells, and ENTECH who is supplying the linear Fresnel concentrator lenses. Fabrication of the DS1 SCARLET solar array wings is nearing completion. Power verification and environmental testing is to start in June 1997 with array delivery to JPL for spacecraft integration occurring in December 1997.

\section{Fresnel Lens}

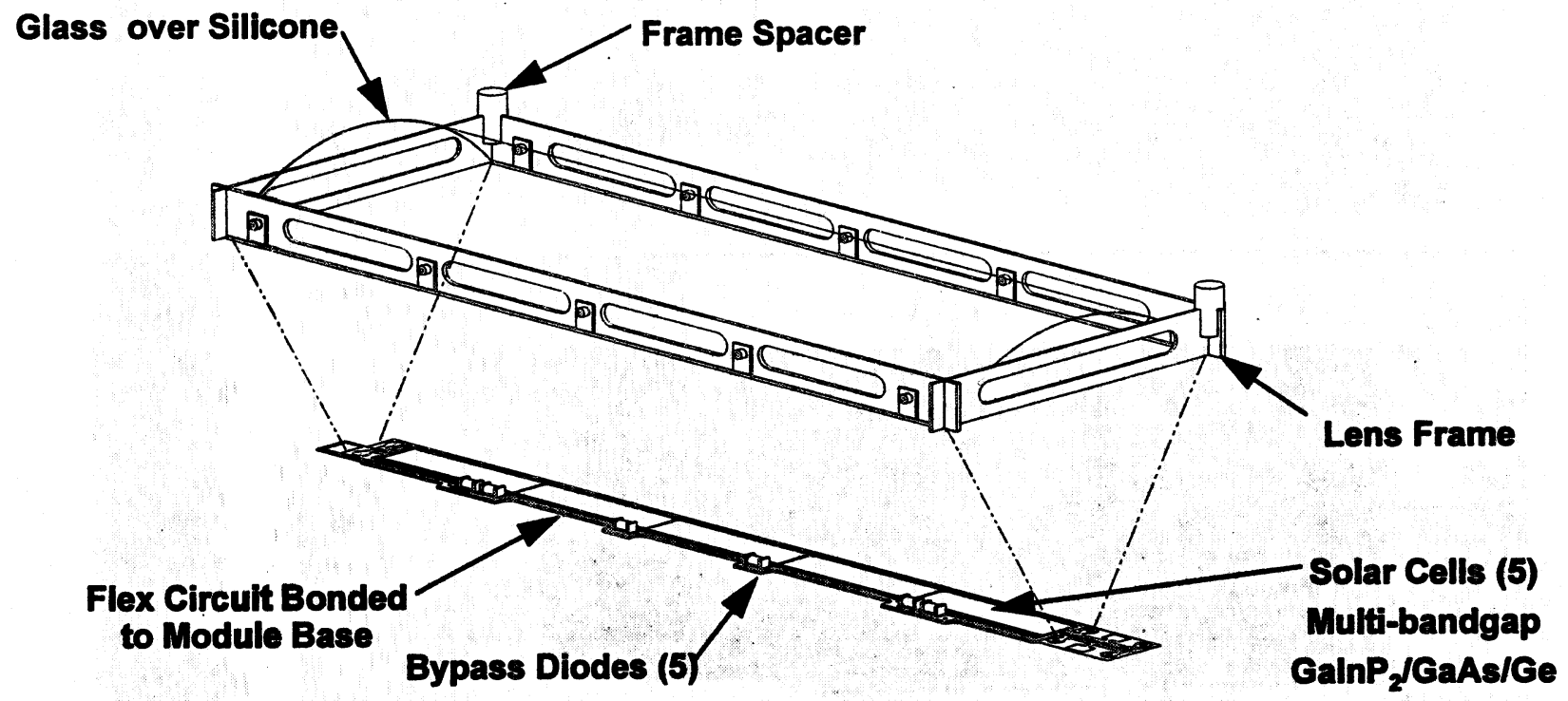

Figure 1. SCARLET Power Module - Building Block of the SCARLET Solar Array

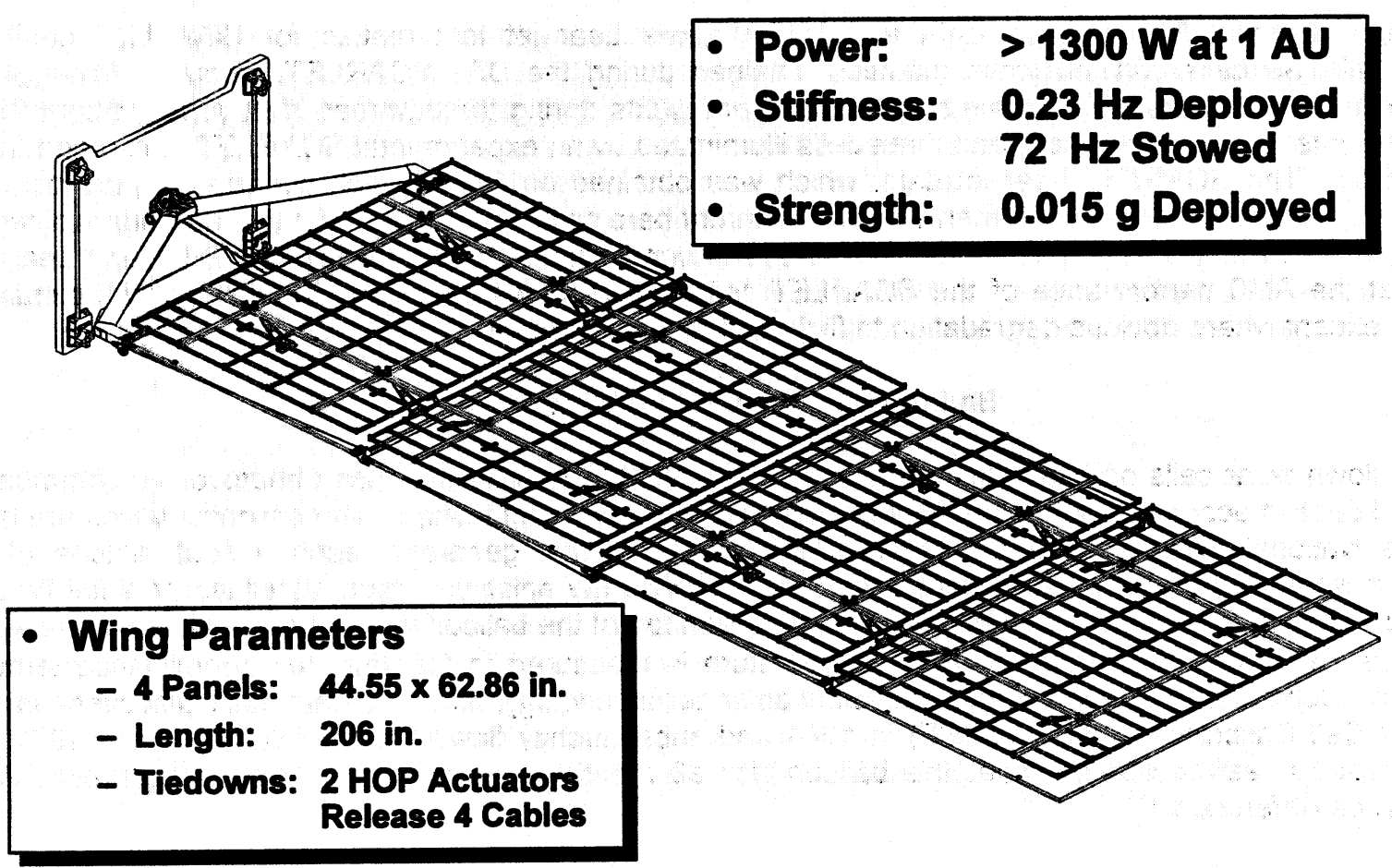

Figure 2. DS1 SCARLET Solar Array Wing 


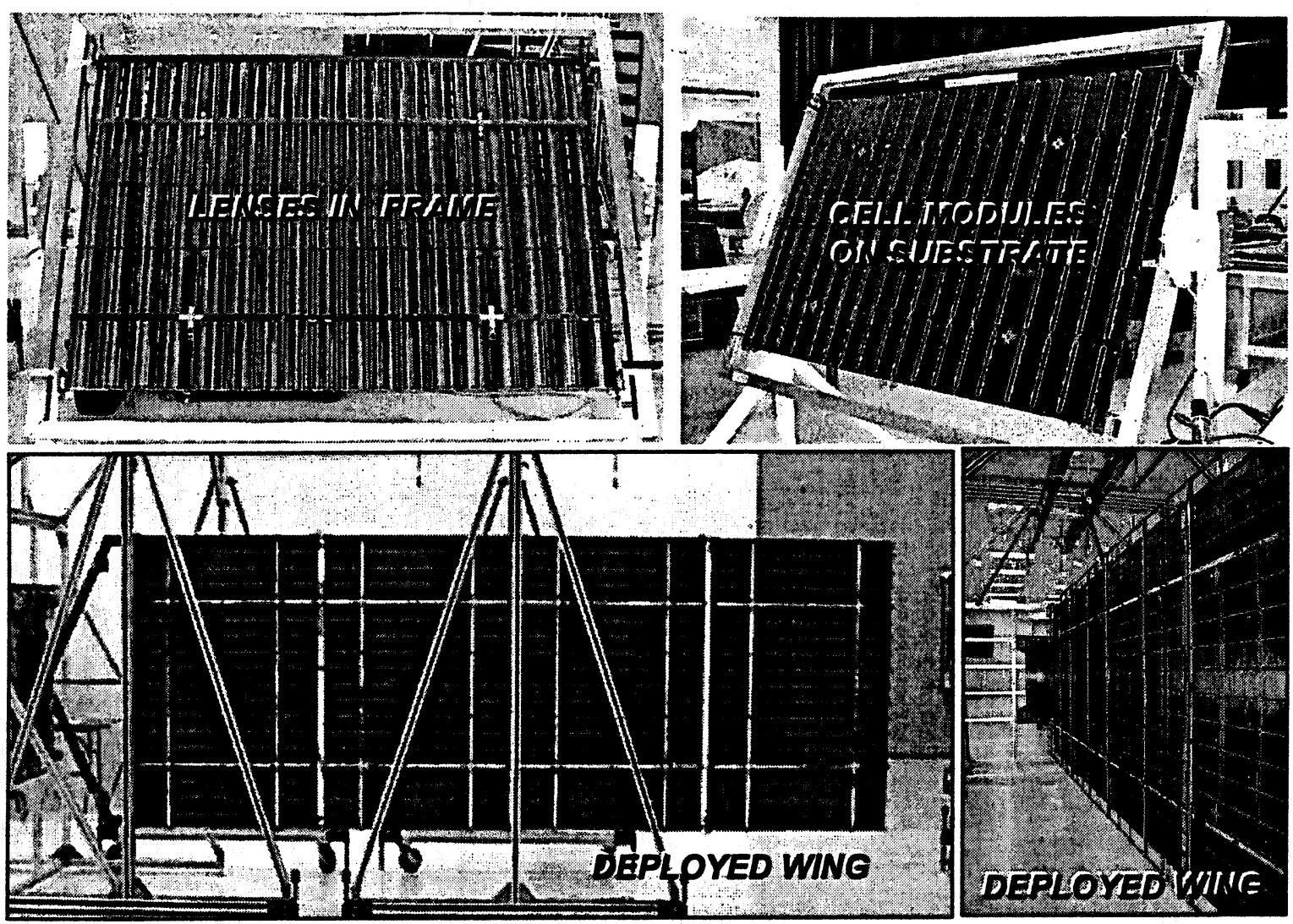

Figure 3. Photographs from DS1 SCARLET Solar Array Wing Manufacturing and Deployment Testing

This paper presents JPL balloon flight and NASA Lewis Lear jet test results for SCARLET dual junction GalnP $\mathrm{P}_{2} / \mathrm{GaAs} / \mathrm{Ge}$ cells and lens/cells modules obtained during the DS1 SCARLET program. The SCARLET balloon flight data, which was obtained on two different flights during the summer of 1996, consists of IV curve measurements for three bare cells and three cells illuminated by an experimental SCARLET lens made from THV fluoroplastic. The SCARLET Lear jet data, which was obtained on flights which occurred during the winter of 1996/1997, consists of Isc measurements for five different bare cells and Isc and IV curve data for two cells under a DS1 flight-like ceria-doped microsheet/DC 93-500 silicone lens. Overall, the balloon flight and Lear jet data show that the AMO performance of the SCARLET cells and modules tested are consistent with simulator test results - except where obvious degradation to flight test articles occurred.

\section{Balloon Flight Solar Cell Measurements}

JPL has flown solar cells on high altitude balloons since 1963 to provide the space photovoltaic community AMO calibrated cells to accurately set solar simulator intensity during ground testing. The balloons, which are launched from the National Scientific Balloon Facility in Palestine, Texas, generally reach a float altitude of around $120,000 \mathrm{ft}$ where the balloon remains for several hours while the solar cell data, either Isc or a full IV curve, is collected. The solar cells are mounted to a sun tracker on top of the balloon which points normal to the sun within \pm 1 degree. The solar cell mounting plate temperature is measured to facilitate cell performance temperature correction. Comparison of a wide cross section of solar cell technology, flown on the shuttle Discovery as a part of the Solar Cell Calibration Facility (SCCF) in 1984 and subsequently flown on the JPL balloon in 1985 showed nearly identical results verifying that the balloon, for all practical purposes, is a true measure of AMO cell performance (reference 1). 


\section{SCARLET Balloon Flight Data}

The SCARLET balloon flight data, which was obtained on two different flights during the summer of 1996, consists of IV curve measurements for three bare cells and three cells illuminated by an experimental SCARLET lens made from THV fluoroplastic. The TECSTAR dual junction $\mathrm{GalnP}_{2} / \mathrm{GaAs} / \mathrm{Ge}$ SCARLET cells flown on the balloon were manufactured during an engineering development program in which 100 cells $(4.2 \times 1.14 \mathrm{~cm})$ were delivered with a lot average efficiency of $24.2 \%$ at $7.5 \times$ AMO uniform illumination. The primary purpose of the balloon flight test was to provide calibration cells for DS1 SCARLET ground testing. The secondary objective was to measure AMO performance of SCARLET power modules utilizing an experimental THV lens.

\section{Bare Cell Data}

The three bare SCARLET cells were flown on the JPL balloon launched on June 10, 1996. A summary of the flight and pre-flight JPL LAPSS data for these cells, corrected to $28^{\circ} \mathrm{C}$, is shown in Tables 1 and 2 . Temperature corrected IV curves from the beginning and end of the flight for cells 96-308 and 96-346 are shown in Figure 4. The average cell parameters during flight were calculated from 152 different IV curves measured over approximately a 3 hour period. Two of the three bare cells showed reduced fill factors and efficiencies in flight compared to the pre-flight JPL LAPSS. Cell 96-138 appears to have been severely damaged, as indicated by its very poor fill factor and efficiency measured in flight. Cell 96-346 showed modest fill factor and efficiency reduction raising questions about its condition. Cell 96-308 performed similarly on both the pre-flight LAPSS and in-flight tests making this cell the best cell for SCARLET ground test calibration until the flight-build cells are calibrated on the 1997 balloon flight.

Table 1. Bare SCARLET Cell Pre-flight JPL LAPSS and Balloon Flight Data Summary - 1 Sun Data

\begin{tabular}{|c|c|c|c|c|c|c|c|c|}
\hline BARE & & & & & & & Voc & \\
\hline CELL No. & LAPSS & |BALLOON & LAPSS & |BALLOON & LAPSS & BALLOON & LAPSS & BALLOON \\
\hline $96-138$ & $22.1 \%$ & $12.5 \%$ & 0.80 & 0.58 & 68.43 & 68.97 & 2.425 & 1.8626 \\
\hline & & & & 0.80 & 67.44 & 68.51 & 2.423 & 2.3761 \\
\hline $96-346$ & $22.0 \%$ & $21.1 \%$ & 0.80 & 0.78 & 68.16 & 67.91 & 2.423 & 2.3803 \\
\hline
\end{tabular}

Table 2. Difference Between Pre-flight JPL LAPSS Data and Balloon Flight Data for Bare Cells

\begin{tabular}{|c|c|c|c|c|c|c|c|c|}
\hline BARE & \multicolumn{2}{|c|}{ EFFICIENCY } & \multicolumn{2}{|c|}{ FILL FACTOR } & \multicolumn{2}{|c|}{$\operatorname{Isc}(\mathrm{mA})$} & \multicolumn{2}{|c|}{$\operatorname{Voc}(V)$} \\
\hline CELL No. & $\Delta$ & (\%) & $\Delta$ & $\%$ & $\Delta$ & (\%) & $\Delta$ & (\%) \\
\hline $96-138$ & -0.096 & -43.44 & -0.22 & -27.50 & 0.541 & 0.79 & -0.562 & -23.19 \\
\hline $96-308$ & -0.001 & -0.46 & -0.01 & -1.23 & 1.067 & 1.58 & -0.047 & -1.94 \\
\hline $96-346$ & -0.009 & -4.09 & -0.02 & -2.50 & -0.255 & -0.37 & -0.043 & -1.76 \\
\hline
\end{tabular}
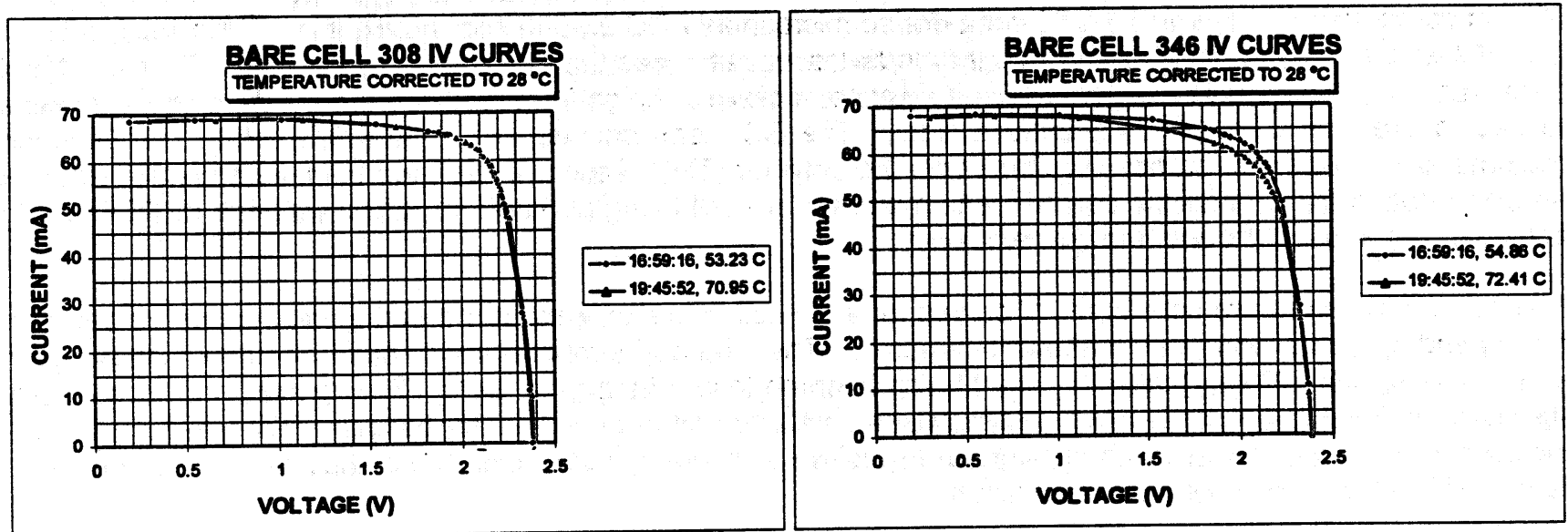

Figure 4. Bare SCARLET Cell IV Curves from June 10, 1996 JPL Balloon Flight 
A post-flight investigation at ABLE has determined the most likely reason for the damage to cells $96-138$ and 96-346 was due to reverse bias encountered either during ground or flight testing. Bypass diodes were not installed on the bare cells because before the flight it was not known that various pieces of test equipment, like LAPSS electronic loads, could produce enough transient reverse bias to damage the cells. This was an important lesson learned and incorporated on subsequent cell and module testing.

\section{Balloon Flight SCARLET Lens/Cell Module Data}

A SCARLET lens module, consisting of three individually wired cells under a single monolithic THV fluoropolymer lens measuring $7.50 \times 3.43$ inches, was flown on the August 8,1996 balloon flight. Figure 5 is a photograph of the SCARLET balloon flight module mounted to the solar tracker during ground testing. The line of focused light on the solar cells created by the SCARLET lens is readily seen in the photograph.

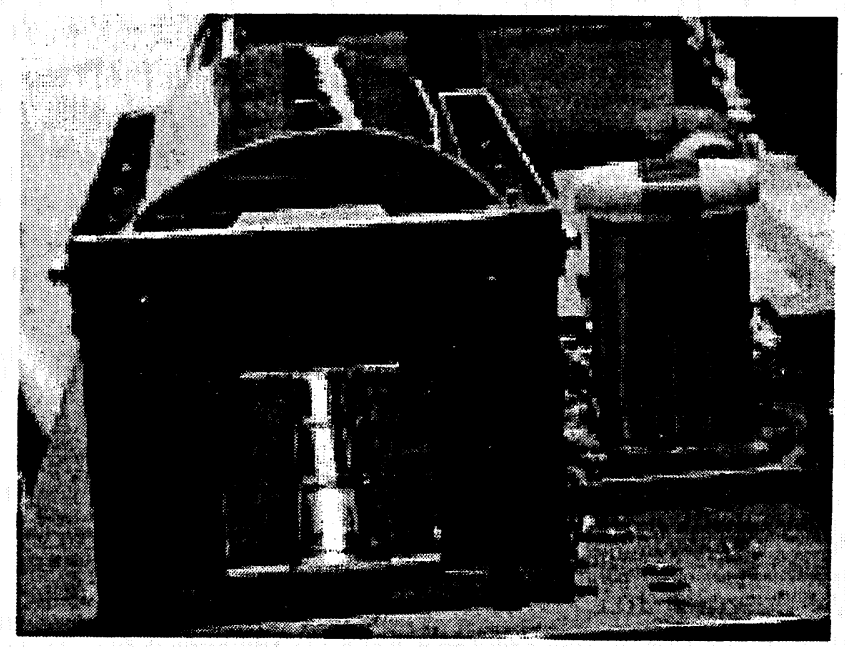

Figure 5. SCARLET Balloon Flight Module on Solar Tracker During Ground Testing

The three cells under the lens were individually wired so that IV curves could be measured separately for each one. A Resistance Temperature Device (RTD) was located in the baseplate under the middle cell (96-304). The measured baseplate temperature was used to calculate the cell junction temperature which is used to adjust cell performance to $28^{\circ} \mathrm{C}$.

The SCARLET balloon flight module THV prototype lens was measured by ENTECH to have an efficiency of only $80 \%$. In comparison, the average DS1 ceria-doped microsheet / DC 93-500 silicone flight lens efficiency is $89.5 \%$. The THV lens was used on the balloon flight module because it was the only DS1-sized SCARLET lens available at the time. The switch to microsheet / silicone lenses, a proven design from previous programs, came after it was too late to prepare a lens for the balloon flight. The DS1 lens change was made to alleviate manufacturing problems and radiation tolerance concerns with the polymer (THV, Teflon, Tefzel, etc.) lenses originally explored. It is worth noting that monolithic polymer lens materials are still being pursued for future versions of SCARLET to decrease cost and weight and improve efficiency.

The raw (non-temperature corrected) IV curves for each cell in the concentrator module obtained at the beginning and the end of the balloon flight is shown in Figure 6. The time and temperature for each IV curve is shown in the legend in the plots. Note, that both Isc and Voc became lower during the flight. The reduction in Voc is easily explained by the negative cell voltage temperature coefficient and the higher temperature at the end of the flight. However, since Isc increases with temperature (positive temperature coefficient), Isc should have been higher at the end of the flight compared to the beginning. 

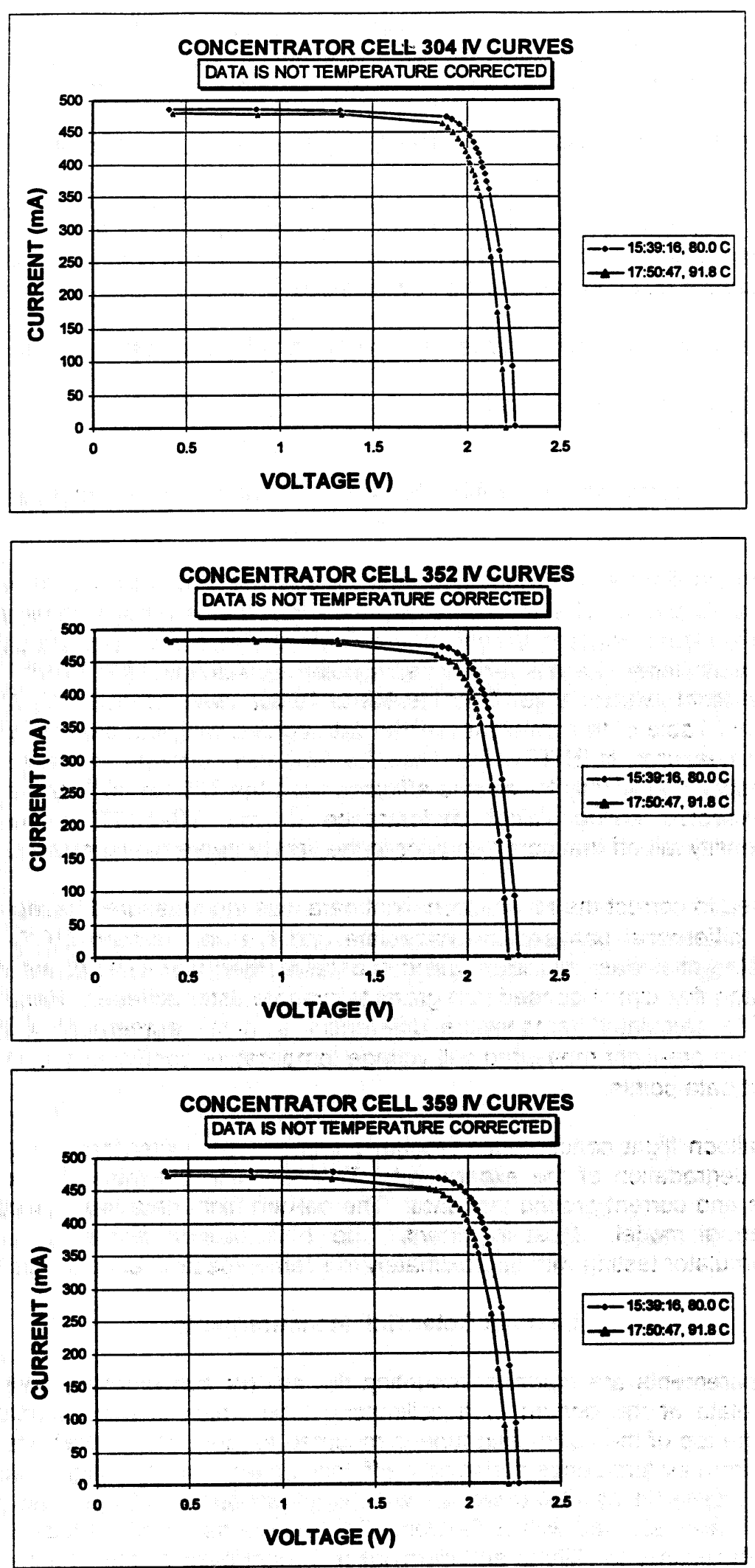

Figure 6. Concentrator Module Cell IV Curves from Beginning and End of Flight - Not Temperature Corrected 
As shown in Figure 7, when voltage and current are temperature corrected, using the JPL measured cell temperature coefficients, no variation in Voc with temperature is observed, but the variation in Isc and thus maximum power becomes larger. In fact as shown in Figure 8, temperature corrected Isc steadily decreased for all cells as a function of flight time most likely indicating a steady reduction in light flux on the cells during flight. The consistency of temperature corrected Voc indicates that the temperature correction is quite accurate.

The exact cause of the light intensity reduction is still not known because unfortunately the balloon payloads on this flight, including the solar cells, descended through a thunderstorm and landed in a muddy field - coating the concentrator module with mud and ruining it. This made post flight analysis somewhat difficult. However, reasons for the performance decrease have been postulated and include:

1. Contamination on lens and cells from outgassing of plywood lens supports installed just prior to flight or from some other source.

2. Rapid lens darkening caused by UV radiation

3. Lens thermal distortion

Further investigation will be performed to explain this result if THV or similar material is pursued as a future SCARLET lens material.

A summary of the balloon in-flight and pre-flight JPL LAPSS data for the concentrator module cells, corrected to $28^{\circ} \mathrm{C}$, is shown in Tables 3 and 4. The flight data presented are the first measurements made during the flight because they represent the least reduction in light intensity. Module efficiency was calculated using an illuminated area equal to the lens width times the cell length and a solar constant of $1367 \mathrm{~W} / \mathrm{m}^{2}$. The SCARLET module efficiency on the balloon flight, which ranged from $19.0 \%$ to $19.5 \%$ was $1.5 \%$ to $4.7 \%$ less than the pre-flight LAPSS data. As shown in Table 5, the pre-flight LAPSS data agreed well with performance predictions based on the $80 \%$ lens efficiency measured at ENTECH and the 7.5 AMO cell performance measured at TECSTAR. The balloon flight data correspond to slightly lower lens efficiencies in the $78 \%$ to $80 \%$ range. The most likely cause for the lower than expected balloon flight performance of the SCARLET concentrator module is the aforementioned light intensity fall-off that occurred prior to the first IV curve measurement.

The cell temperature used to correct the raw balloon flight data was the measured baseplate temperature plus the calculated temperature differential between the baseplate and the cell junction $\left(15.6{ }^{\circ} \mathrm{C}\right)$. The baseplate-tojunction temperature differential was calculated using a detailed thermal model of the balloon flight cell carrier which consists of a Kapton flex circuit bonded to a graphite/cyanate ester stiffener. Results of this calculation are shown in Figure 9. The calculated temperature differential is in fair agreement with that derived from the measured cell Voc and the pre-flight measured cell voltage temperature coefficients - which ranged from $17.2^{\circ} \mathrm{C}$ to $18.0^{\circ} \mathrm{C}$ for all 65 flight data points.

While the SCARLET balloon flight concentrator produced slightly less power than expected, most likely due to contamination induced degradation of the experimental THV lens, it otherwise appears that the flight data is consistent with previous and current ground test data. The balloon flight data has helped validate and refine the SCARLET receiver thermal model. Most importantly, the 1996 balloon flights produced calibrated cells for SCARLET array solar simulator testing with approximately the same spectral response as the DS1 flight cells.

\section{Lear Jet Solar Cell Measurements}

Lear jet solar cell measurements are made by mounting the cell (or concentrator module) on a 3-inch-square, temperature-controlled plate at the bottom of a collimating tube which is approximately 20 inches long and 6 inches in diameter. The top of the collimating tube is mounted to the fuselage wall beneath an external shutter which protects the cells from air turbulence during take off, landing and low level flight. During cell measurements the protective shutter is opened, illuminating the cell with direct unfiltered sunlight. Sun pointing is controlled by the pilot. Lear IV curves are recorded with a Tektronix 370A curve tracer controlled with a Grid 386 computer. Timing of the curves with regards to altitude and illumination is controlled by the copilot. Cell Isc measurements are made on the Lear jet by loading each cell with a precision resistor ( 0.1 ohms in this case) and measuring the voltage drop across the resistor. 

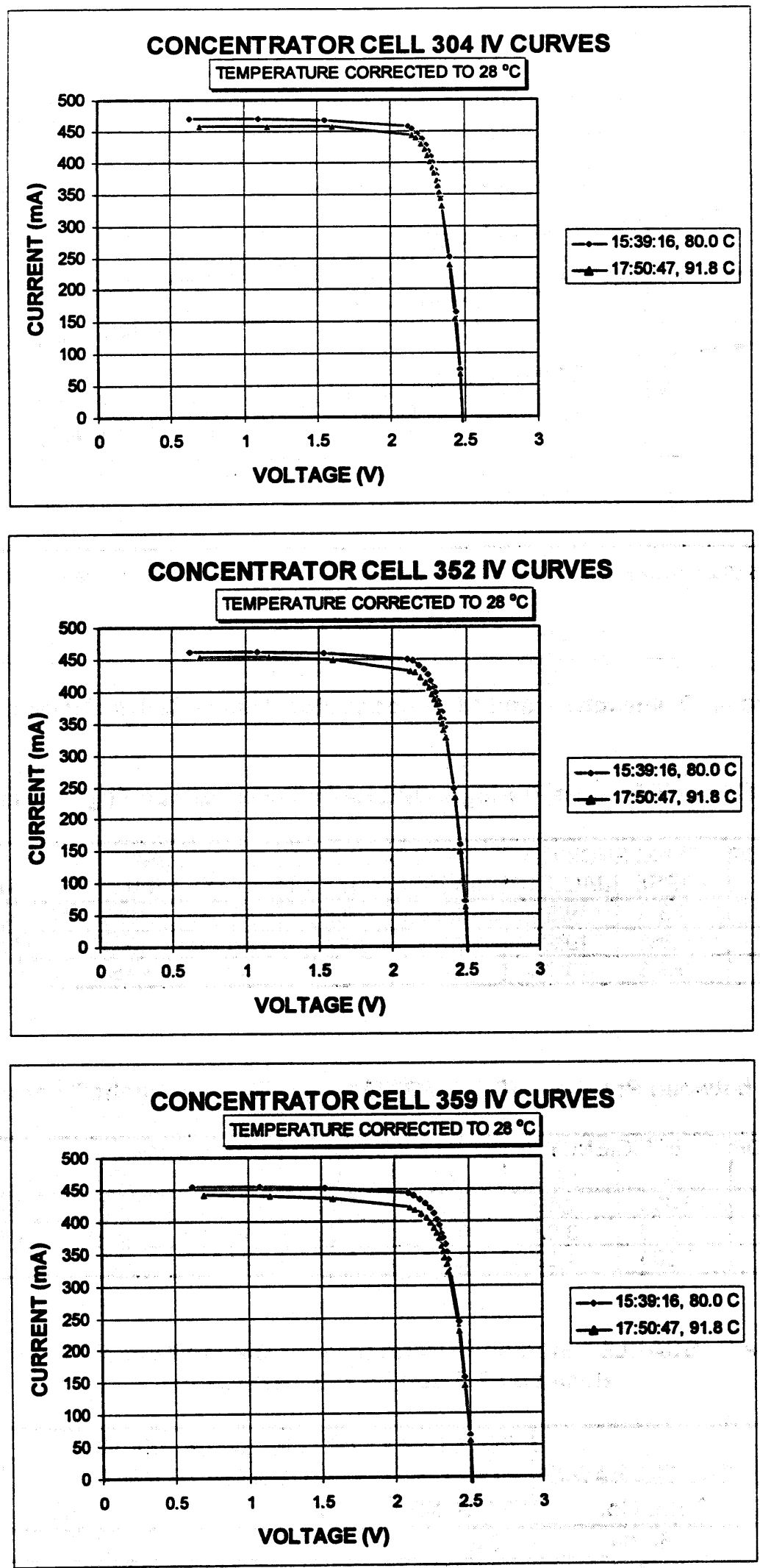

Figure 7. Concentrator Module Cell IV Curves from Beginning and End of Flight -Temperature Corrected 


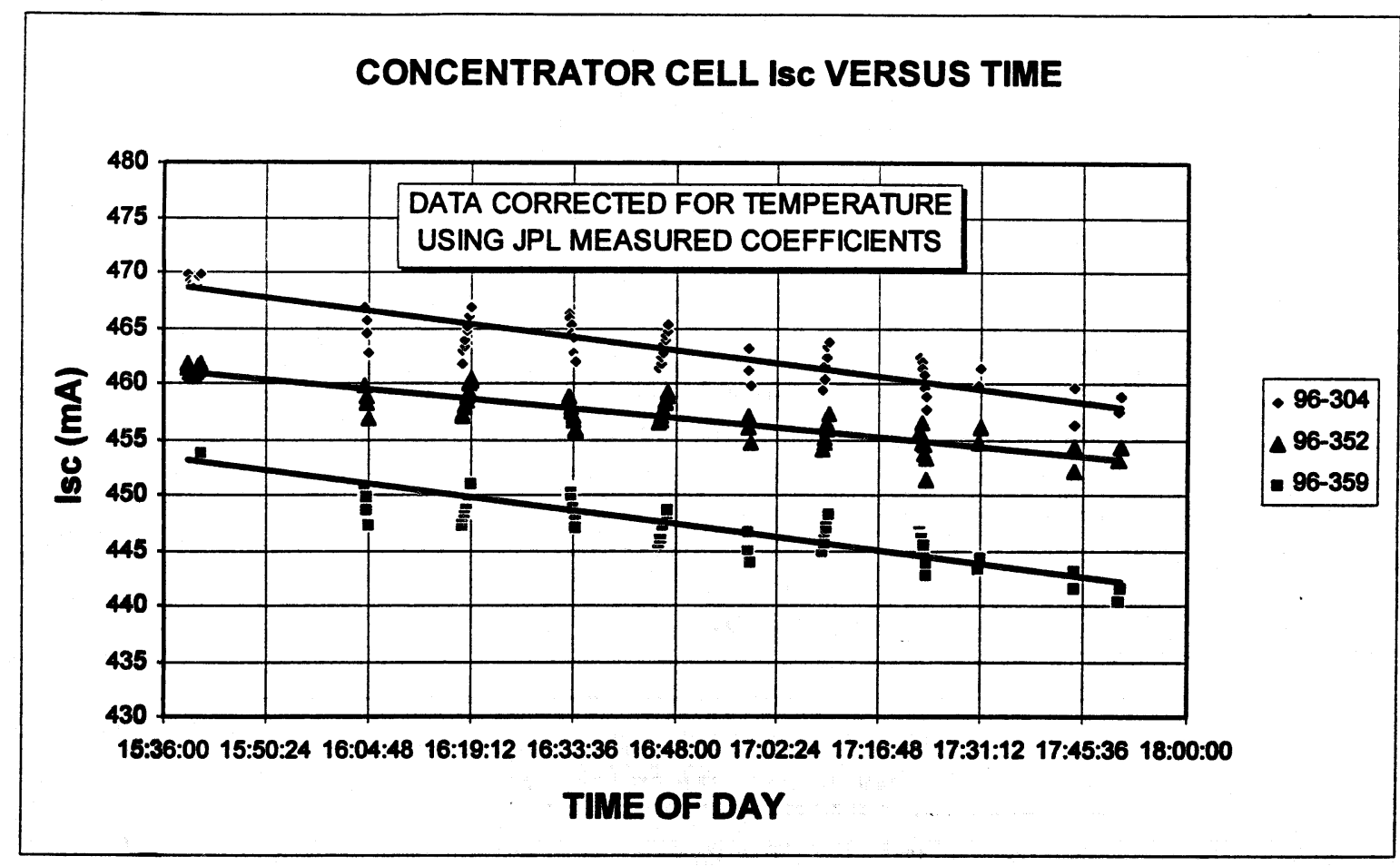

Figure 8. Downward Trend of Concentrator Module Cell Isc Versus Time

Table 3. SCARLET Module Pre-flight JPL LAPSS and Balloon Flight Data Summary

\begin{tabular}{|c|c|c|c|c|c|c|c|c|}
\hline $\begin{array}{l}\text { CONCENTRATOR } \\
\text { CELL No. }\end{array}$ & \multicolumn{2}{|c|}{$\begin{array}{l}\text { EFFICIENCY (\%) } \\
\text { LAPSS |BALLOON }\end{array}$} & \multicolumn{2}{|c|}{$\begin{array}{l}\text { FILL FACTOR } \\
\text { FPSS }\end{array}$} & \multicolumn{2}{|c|}{$\operatorname{Isc}(m A)$} & \multicolumn{2}{|c|}{$\operatorname{Voc}(N)$} \\
\hline $96-304$ & $19.8 \%$ & $19.5 \%$ & 0.82 & 0.83 & 481.73 & 469.6 & 2.493 & 2.485 \\
\hline & & & & & & & & \\
\hline & 190 & $19.0 \%$ & 0.81 & 0.83 & 481.51 & 7 & 2.536 & 2.522 \\
\hline
\end{tabular}

Table 4. Difference between Pre-flight JPL LAPSS Data and Balloon Flight Data for SCARLET Module

\begin{tabular}{|c|c|c|c|c|c|c|c|c|}
\hline CONCENTRATOF & EFFI & ENCY & FILL & TOR & & & & \\
\hline CELL No. & $\Delta$ & (\%) & $\Delta$ & $\%$ & $\Delta$ & (\%) & $\Delta$ & (\%) \\
\hline $96-304$ & -0.003 & -1.52 & 0.01 & 1.22 & -12.130 & -2.52 & -0.008 & -0.32 \\
\hline $96-352$ & -0.006 & -3.03 & 0.01 & 1.22 & -14.340 & -3.01 & -0.022 & -0.87 \\
\hline $96-359$ & -0.009 & -4.52 & 0.02 & 2.47 & -27.810 & -5.78 & -0.014 & -0.55 \\
\hline
\end{tabular}

Table 5. SCARLET Module Performance for Different Lens Efficiencies Based on 7.5 Sun LAPSS Test Results

\begin{tabular}{|c|c|c|c|c|}
\hline \multirow{2}{*}{$\begin{array}{c}\text { CONCENTRATOR } \\
\text { CECSTAR }\end{array}$} & \multicolumn{3}{|c|}{$28{ }^{\circ} \mathrm{C}$ MODULE EFFICIENCY } \\
LEL NO. & LAPS & \multicolumn{2}{|c|}{ AT LENS EFFICIENCY: } \\
\hline $96-304$ & $24.49 \%$ & $19.1 \%$ & $19.6 \%$ & $22.0 \%$ \\
\hline $96-352$ & $24.53 \%$ & $19.1 \%$ & $19.6 \%$ & $22.1 \%$ \\
\hline $96-359$ & $24.47 \%$ & $19.1 \%$ & $19.6 \%$ & $22.0 \%$ \\
\hline
\end{tabular}




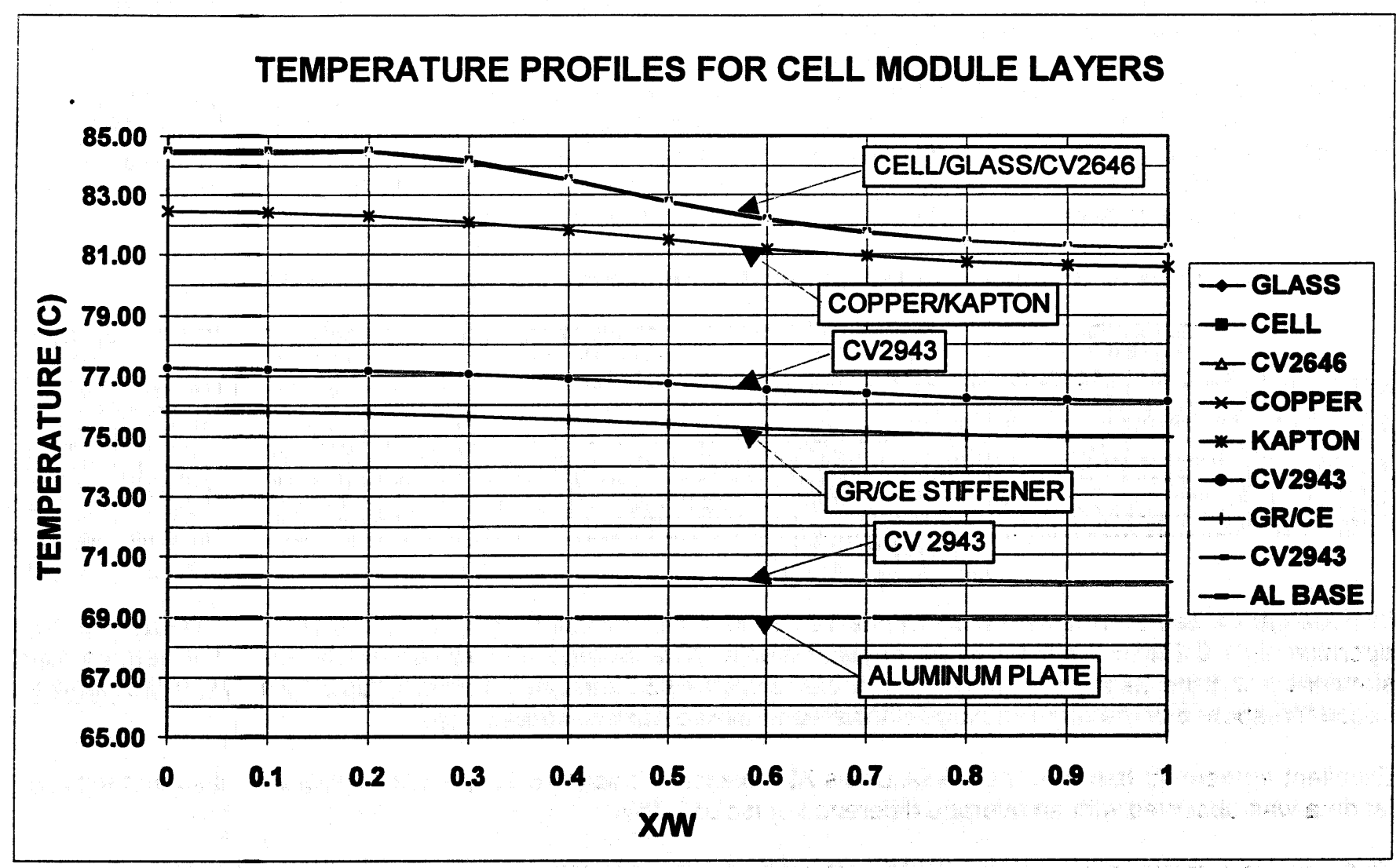

Figure 9. Balloon Flight Cell Carrier Thermal Analysis Results

( $x / w=0$ corresponds to the cell centerline (line of symmetry) and $x / w=1$ is the cell edge)

Data is taken at several altitudes starting at a peak altitude of typically $48,000 \mathrm{ft}$. Barometric pressure is continually monitored and the equation:

where

$$
\text { Air Mass = PI (Po } \cos \text { (L-D)) }
$$

$$
\begin{aligned}
& P=\text { pressure } \\
& P_{0}=\text { standard sea level pressure }=14.69 \text { psia } \\
& L=\text { latitude } 45^{\circ} \text { north in our case } \\
& D=\text { declination angle (which varies daily) }
\end{aligned}
$$

is used to determine the air mass of each data point. A Langley plot of log(Isc) versus air mass is made and the AMO Isc is determined by extrapolation. Typically the Isc measured at peak altitude is greater than $95 \%$ of the AMO Isc, so the extrapolation to AMO is small.

\section{Lear Jet SCARLET Data}

The SCARLET Lear jet data, which was obtained on flights which occurred during the winter of 1996/1997, consists of IsC measurements for five different bare SCARLET cells and IsC and IV curve data for two cells under a DS1 flight-like, ceria-doped microsheet/DC 93-500 silicone lens. The SCARLET cells flown on the Lear jet were obtained from early DS1 production runs. For various process related reasons the TECSTAR production cells, which measure $4.06 \times 1.12 \mathrm{~cm}$, are generally lower performing than the engineering development SCARLET cells (flown on the JPL balloon flight the previous summer), with an average lot efficiency of $22.7 \%$ at $7.5 \times$ AMO uniform 
illumination. The Lear jet data is used for cross-checking ground solar simulator testing and to measure lens optical efficiency and overall module performance.

Isc data for both the bare SCARLET cells and the lens/cell modules flown on the Lear jet are presented in Table 6. For comparison, Isc data measured with several solar simulators including the NASA Lewis X25, the TECSTAR Hoffman 2 and Hoffman 10 and the JPL LAPSS is also shown in Table 6. While the sample size (6) is too small to draw hard quantitative conclusions the trends observed in the data are informative. The variation in the test results is indicative of the sensitivity of dual-junction cells to simulator spectrum accuracy.

Table 6. Summary of Lear Jet and Solar Simulator Isc Data for SCARLET Cells

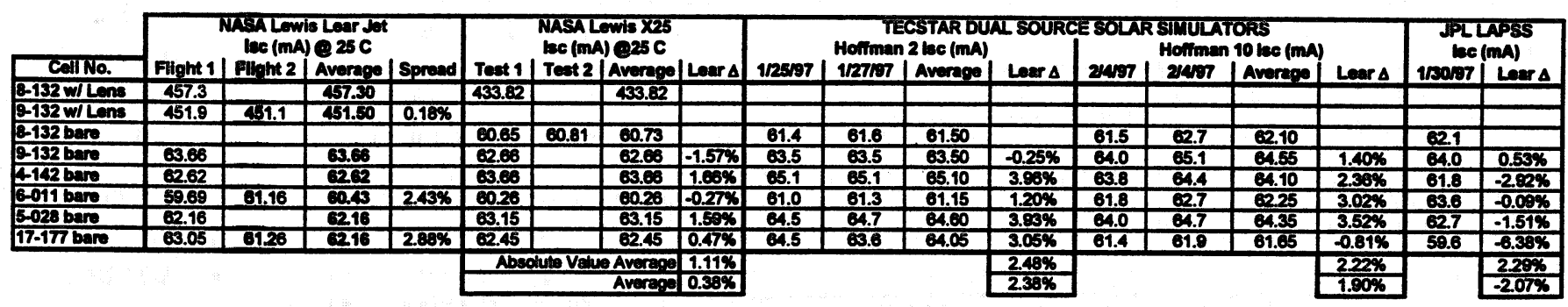

In three cases, cell or module Isc was measured on two different Lear jet flights with a repeatability ranging from approximately $0.2 \%$ to $2.9 \%$ for these measurements. On average, the agreement between the various solar simulators and the Lear jet Isc data was in the $-2.0 \%$ to $+2.3 \%$ range, which is good considering the complex spectral response of the dual-junction cells tested and experimental uncertainties.

Excellent agreement between the NASA Lewis X25 (xenon arc source, dual junction calibration cell) and the Lear jet data was observed with an average difference of Isc of $0.38 \%$.

The cell Isc's measured with the TECSTAR Hoffman 2 and Hoffman 10 (dual xenon and tungsten source calibrated with both a dual junction cell and separate top and bottom junctions of a dual junction cell design) were higher on average compared to the Lear jet data by approximately $2 \%$, as shown in Figure 10.

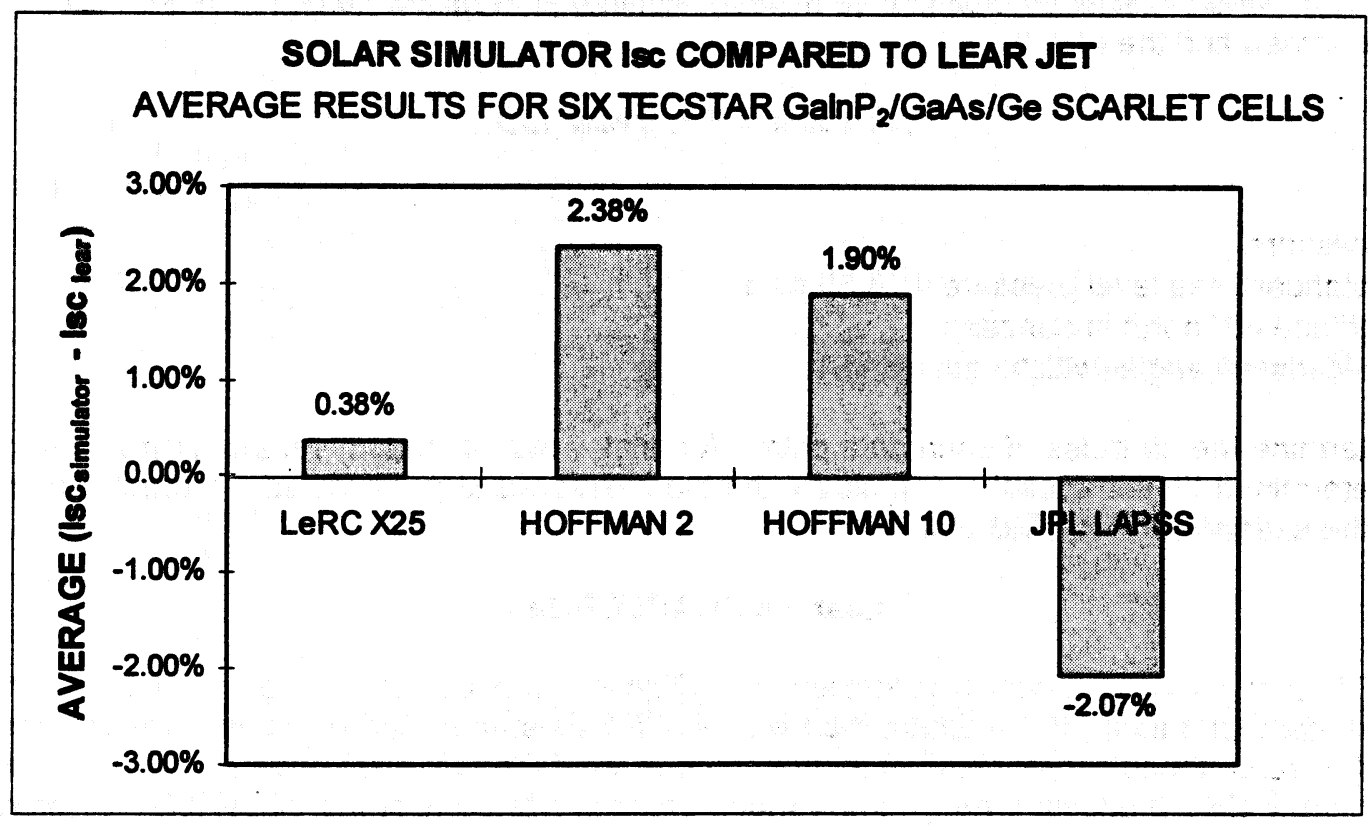

Figure 10. Comparison of Average lsc Measured on Lear Jet to Various Solar Simulators for Five SCARLET Cells 
The cell Isc measurements taken with the JPL LAPSS (pulsed xenon arc source with Schott GG-395 UV filter (reference 2), GaAs calibration cell) were lower on average than the Lear jet data by about $2 \%$.

The major significance of this data for the DS1 SCARLET program is that it suggests that the SCARLET cell AMO power may have been slightly overrated $(-2 \%)$ by TECSTAR's simulator. This is because TECSTAR used Hoffman 10 isc to correct the $7.5 \times$ AMO LAPSS performance data for each flight cell. This was necessary because balloon flight calibration cells of the exact spectral response of the DS1 production cells were not available during LAPSS testing so calibration using the Hoffman 10, which has a spectrum that matches AMO better than the LAPPS, was thought to be the best alternative. Two cells, representative of the DS1 flight build, are being calibrated on the JPL balloon flight this June and will enable more accurate measurement of the DS1 array power.

\section{Lear Jet Lens Optical Efficiency}

The DS1 SCARLET lenses consist of a silicone Fresnel lens bonded to a ceria doped microsheet superstrate which provides structural support and UV radiation protection. ENTECH successfully built, tested and delivered on time 800 lenses (includes 80 spares) for the DS1 SCARLET program with an average measured optical efficiency of $89.5 \%$.

The DS1 SCARLET lenses are 3.36 inches wide by 8.38 inches long and focus light onto a 5 solar cell receiver. For Lear jet testing short lenses, 2.0 inches long, illuminating a single cell were manufactured to fit in the collimating tube. A photograph of the Lear jet SCARLET test module is shown in Figure 11.

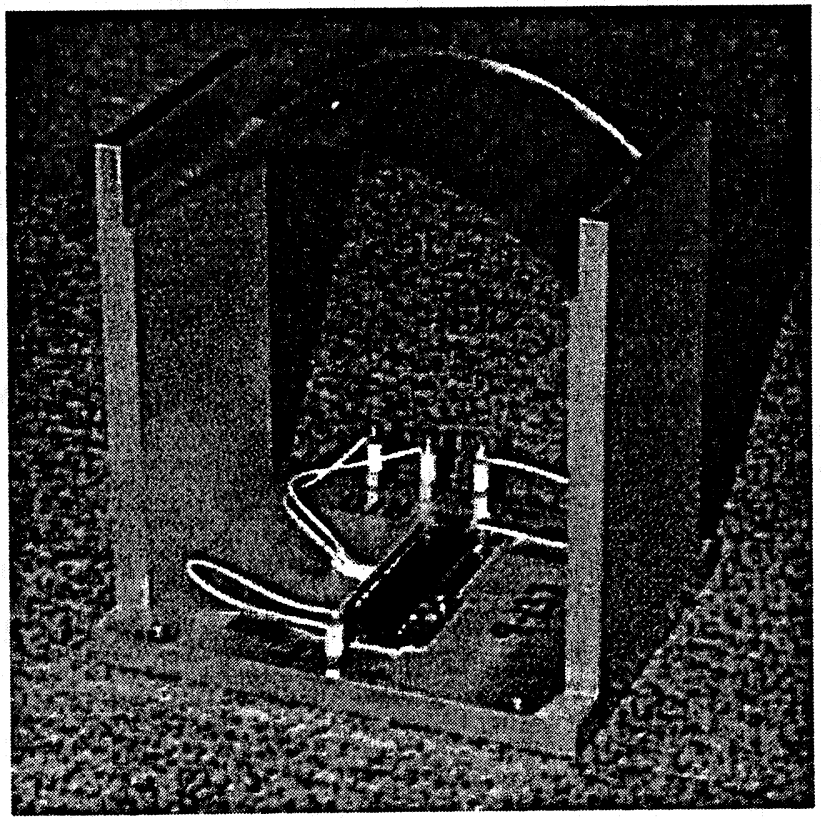

Figure 11. SCARLET Module for Lear Jet Testing

Lens efficiency, for flight-like DS1 SCARLET lenses, was measured in near AMO sunlight during the Lear jet tests to validate the lens efficiency measurements made during lens manufacturing. Good agreement was found.

Since solar cell Isc varies in direct proportion to light intensity, the measurement of SCARLET cell Isc both bare and lens illuminated allows for the calculation of lens optical efficiency through the equation:

$$
\text { Lens efficiency }=\left(\text { Isc }_{L} / \text { Isc }_{B}\right) *\left(W_{\text {coll }} / W_{\text {lens }}\right)
$$


Where

$$
\begin{aligned}
& I_{L}=\text { Lens illuminated cell short circuit current } \\
& I_{L}=\text { Bare cell short circuit current } \\
& \mathbf{W}_{\text {cell }}=\text { Active cell width (does not include bus bars) }=0.402 \text { inches } \\
& \mathbf{W}_{\text {lens }}=\text { Lens aperture width }=3.22 \text { inches }
\end{aligned}
$$

Applying this equation to the Lear jet data obtained for cell 9-132 a lens efficiency of $88.5 \%$ is calculated. This compares very favorably to the $89 \%$ lens efficiency measured for this lens during in-process acceptance testing at ENTECH where a collimated tungsten light source and a flight-like cell receiver are used.

Unfortunately the Lear jet winter flight season ended before cell 8-132 could be flown bare (it had already been flown with a lens). However, using the NASA Lewis X25 bare cell Isc and the Lear jet cell-with-lens Isc for cell $8-132$, a lens efficiency of $94.0 \%$ was calculated. The NASA Lewis X25 bare cell Isc is used because it matches the Lear jet results best for these cells. This Lear jet lens efficiency for module 8-132 is significantly higher than the $90 \%$ lens efficiency measured during acceptance testing at ENTECH due to experimental uncertainties.

The Lear jet test results for the two SCARLET modules suggest the AMO lens efficiency is approximately the same or perhaps slightly more than measured during acceptance testing at ENTECH.

\section{Conclusion}

Several successful SCARLET experiments with both bare cells and lens/cell modules were completed on both the JPL balloon, during the summer of 1996, and the NASA Lewis Lear jet, during the winter of 1997. Generally, agreement between the flight data and the several different types of solar simulators used, which include the X25, Hoffman 2, Hoffiman 10 and LAPSS, is good - except in the cases where obvious degradation occurred in flight. The Lear jet test results for five bare SCARLET cells suggest the DS1 SCARLET flight cells may produce slightly less power in space then predicted by the Hoffiman 10. The Lear jet test results for the two SCARLET modules suggest the AMO lens efficiency for the DS1 ceria-doped microsheet / DC 93-500 lenses is approximately the same or perhaps slightly more than measured during acceptance testing at ENTECH.

\section{References}

1. Anspaugh, B. E. and Weiss, R. S., Results of the 1996 JPL Balloon Flight Solar Cell Calibration Program, JPL Publication 97-5, December 1996.

2. Mueller, R. L., The Large Area Pulsed Solar Simulator (LAPSS), JPL Publication 93-22, Rev. A., July 1994. 